\title{
THE
}

\section{The Pricing of Community Supported Agriculture Shares: Evidence from New England}

Thomas W. Sproul

University of Rhode Island, sproul@uri.edu

Jaclyn D. Kropp

Kyle D. Barr

University of Rhode Island

Follow this and additional works at: https://digitalcommons.uri.edu/enre_facpubs

The University of Rhode Island Faculty have made this article openly available.

Please let us know how Open Access to this research benefits you.

This is a pre-publication author manuscript of the final, published article.

Terms of Use

This article is made available under the terms and conditions applicable towards Open Access

Policy Articles, as set forth in our Terms of Use.

\section{Citation/Publisher Attribution}

Sproul, T., Kropp, J. and Barr, K. (2015), "The pricing of community supported agriculture shares: evidence from New England", Agricultural Finance Review, Vol. 75 No. 3, pp. 313-329. https://doi.org/10.1108/

AFR-04-2015-0020

Available at: https://doi.org/10.1108/AFR-04-2015-0020

This Article is brought to you for free and open access by the Environmental and Natural Resource Economics at DigitalCommons@URI. It has been accepted for inclusion in Environmental and Natural Resource Economics Faculty Publications by an authorized administrator of DigitalCommons@URI. For more information, please contact digitalcommons-group@uri.edu. 


\section{The Pricing of Community Supported Agriculture Shares: \\ Evidence from New England}

\section{Structured Abstract}

Purpose: Community Supported Agriculture (CSA) programs allow consumers to buy a share of a farm's production while providing working capital and risk management benefits for farmers. Several different types of CSA arrangements have emerged in the market with terms varying in the degree to which consumers share in the farm's risk. No-arbitrage principles of futures and options pricing suggest that CSA shares should be priced to reflect the degree of risk transfer.

Methodology: We evaluate the three most common share types using a cross-sectional dataset of 226 CSA farms from New England to determine if there is empirical evidence in support of the theoretical price relationship between share types.

Findings: The degree of risk transfer from farmers to consumers has a significant effect on the share price. There are statistically significant returns to scale and higher prices for organics. Farm characteristics and product offerings predict which type of shares is offered for sale.

Research limitations: The data set does not contain information pertaining to actual deliveries, expected deliveries, variance of expected deliveries, or covariance information; thus differences in share prices could be due to differences in these uncontrolled factors.

Value: This paper provides empirical evidence that CSA share prices reflect the degree of risk transferred from the producer to the consumer. It also highlights challenges in conducting empirical work pertaining to CSA contracting.

Keywords: agricultural marketing, community supported agriculture, local food, organic production, risk premium, risk sharing

JEL Codes: Q13, Q14 


\section{Introduction}

In recent years, consumers have become increasingly concerned with where their food is produced. This trend has led to farmers engaging in more direct marketing efforts, such as directto-consumer sales at farmers markets and offering Community Supported Agriculture (CSA) programs. CSA programs let consumers buy "shares" of a farm's production, and therefore are an important part of local food systems and farm-to-table movements. These contractual arrangements also provide benefits to the farm in the form of working capital and risk management features. Since CSA contracts are sold prior to harvest, the farmer can use the CSA contract proceeds to finance expenses incurred during the growing season. Because these contractual arrangements enable the farm to transfer part of its risks to the consumer, CSA contracts are also an important risk management tool for farmers. Recently, a variety of CSA share types (contractual arrangements) have emerged in the market. These share types vary in the degree to which consumers share in the farm's risks.

The concept of CSA programs originated in Japan and Europe in the 1960s and reached the United States by the 1980s (Wilkinson 2001). The first CSA shares in the United States were offered in the New England region, but the concept quickly spread throughout the country. According to Census of Agriculture data, by 2012 over 12,600 U.S. farms were offering CSA programs (U.S. Departments of Agriculture 2014a).

While CSA programs have become increasing popular in the United States, the pricing of CSA shares is not well understood. Prior research has suggested that CSA shares are priced to cover the farm's operating costs (Tegtmeier and Duffy 2005; Brown and Miller 2008; Fieldhouse 1996). Yet, studies indicated that farmers offering CSA shares are frequently unable to satisfactorily cover their costs (Lass et al. 2003; Tegtmeier and Duffy 2005). This suggests other factors may be driving CSA contract prices. Sproul and Kropp (forthcoming) (hereafter SK) 
derive a theory of CSA share contract pricing based on the degree to which the contract transfers the risk of the farmer to the consumer. Their theory is constructed using product-level price and yield expectations and no-arbitrage principles of futures and options pricing. However, CSA programs generally offer a basket of commodities; thus, we extend a key proposition of their theoretical model to basket of commodities. We show that the price relationship between the two most common share types holds even when contracting is on a basket of goods. In addition, we use their dataset of $226 \mathrm{New}$ England CSA farms to empirically evaluate the price relationships between the most common share types.

We find that degree of risk transfer has a significant effect on price: shares that provide pre-specified amounts (weights) of specific products are more expensive than shares in which the consumers receive a percentage of the farm's actual production (and share in the farm's income risk). These shares cost, on average, $\$ 11.93$ (38\%) more per delivery than prices when consumers share in the full yield risk. We also find significant evidence of returns to scale in terms of discounting for longer contracts (more deliveries). Prices per delivery are relatively constant across shares including fruits, vegetables, herbs and cut flowers, but CSA shares providing dairy and/or meat products cost $\$ 2.31$ more per delivery, on average, and per-delivery prices for organic shares are $\$ 3.74$ higher, on average. We also find that the share type offered by a farm is predicted by farm characteristics and by the product(s) produced on the farm. The coefficient estimates for share types and returns to scale are robust to controlling for selection into share types, but the price premium for dairy/meat products is not.

\section{Background}

Farms offering CSA programs sell "shares" in their farm, typically before planting, with the promise that "shareholders" will receive a portion of the farm's harvest. Most farms' CSA shares 
provide the shareholder with a basket of products (up to and including all product varieties grown on the farm); however, other farms offering CSA programs specify only one product or few products to be included in their shares. Although the contractual structure of CSA programs varies from farm to farm, shareholders, referred to as "members", share in the risks of farming and, by paying in advance, provide the farm with working capital during the growing season. However, the exact contract terms pertaining to risk sharing are generally informal; very few CSA share agreements stipulate the course of action should there be a full loss of farm production due to disease, pests, or weather events, such as tornadoes, droughts or floods. Regardless, CSA programs serve as an important risk management tool for farmers who may have limited access to Federal crop insurance programs. CSA programs allow producers to obtain higher prices for their crops, improve the farm's financial security, and reduce the burden of marketing the farm's commodities at harvest (USDA 2014b). In return, members have access to locally grown, fresh products throughout the season, as well as some protection against price risk.

Share agreements are written for a "season," which is normally 8-14 or 20-26 weeks. Throughout the season, members typically pick up their portion of the harvest at the farm or a farmers market each week (or bi-weekly); however, some CSA farms deliver the commodities directly to their members' homes or places of business.

Although a variety of share types have arisen to meet the needs of farmers and consumers, the majority of CSA farms offer shares in which the shareholders receive a specific percentage of the various covered commodities produced by the farm throughout the season. Under this share type, the exact amount (weight) of each product to be received at each pickup (or delivery) is not specified in the CSA agreement; instead, the amount depends on actual 
production. Essentially, by purchasing a share, the shareholder purchases a percentage of the farm's revenue to be paid out in commodities at harvest. Hence, the member shares in the farm's combined production (yield) and price risks. We refer to these arrangements as "yield shares."

In contrast, other farms offer CSA shares that clearly specify the products and quantities (or weights) of each product to be delivered at harvest. We refer to these arrangements as "weight shares." Because the farm has committed to selling a pre-specified quantity at a fixed price, these shares arrangements are similar to futures or forwards contracts. Weight shares remove the price risk for both consumer and producer; however, the farm bears the full burden of the yield risk. In agricultural production, the negative correlation between prices and yields enables price risk to act as a natural hedge against yield risk. This means weight shares cause the farmer to bear yield risk without the benefit of price risk as a natural hedge.

Another type of CSA share arrangement resembles a debit system in which members purchase shares at the beginning of the season and receive a fixed dollar amount in a declining balance account to throughout the season. These members generally receive an explicit discount (usually $10 \%$ ) off of prevailing market prices when making purchases using their pre-paid debit account. We refer to these arrangements as "debit shares." Although these members do not share directly in the farm's yield or price risks, by paying in advance, they still provide working capital to the farm. The final type of CSA shares is "you-pick." Under these contractual arrangements, members make selections among similarly-valued options at each pickup. Because choices are arranged according to market value, you-pick share are similar to debit shares in terms of the degree of risk transfer and hence we group them together in the analysis that follows.

While there are numerous academic studies regarding CSA programs, the majority of these studies analyze the determinants of consumer participation, the benefits of participation to 
producers or consumers, or the benefits to rural communities (see Brown 2002 and Brown and Miller 2008 for a review of this literature). Several studies also investigate the determinants of CSA share prices. Some studies suggest that farm operators price CSA shares to cover the CSA programs operating costs (Tegtmeier and Duffy 2005; Brown and Miller 2008; Fieldhouse 1996). Using data from a survey of 62 CSA operations in the mid-west, Tegtmeier and Duffy (2005) found that CSA share prices were set by the farm owner for $76 \%$ of the farms in their sample. Farm owners indicated that the CSA program operating costs were an important consideration when setting prices. The owners also indicated they considered their own labor costs when setting prices, but not to the same extent that they considered general operating expenses. The same study found that farmers were frequently unsatisfied with their CSA program's ability to cover costs. Another study by Lass et al. (2003) found that only $46 \%$ of respondents to a 2001 national survey were satisfied with their CSA program's ability to cover operating costs. Using four years of survey data from CSA farms in the Northeast United States, Lizio and Lass (2005), in a working paper, found that CSA farms cover their costs only if farm operator's labor is not included. In addition, they found the CSA farms are primarily price takers, consistent with Connolly and Klaiber's (2014) (hereafter CK) finding that CSA farms exhibit little market power. This suggests CSA share prices are not determined solely by production costs.

Few prior studies discuss the various differentiating features of share agreements that have emerged. One noteworthy exception is a study of two CSA farms in the Ithaca, NY area presented in an extension bulletin by Conner (2003). He found the value of the CSA program to the consumer, relative to purchasing the produce elsewhere, depended on whether or not the consumer picked their own produce. SK defined three types of CSA contractual arrangements 
(those discussed above): weight shares, yield shares, and debit/you-pick shares. Their model predicts that contracts in which consumers do not share in production risk, such as weight shares, will be priced higher than shares in which the consumer shares in both price and yield risk, such as yield shares, all else equal. The higher price for weight shares is due to a risk premium. They also show that a farmer's decision to offer CSA shares, which type of shares to offer, and the prices of those shares depend on the farmer's risk preferences, the yield distributions of her crops, and the covariances between revenues and yields of her crops. The current paper fills the gap in the existing literature by testing the predictions of the theoretical model using a broad, cross-sectional data set of New England CSA programs.

Our work also builds on that of CK. Using data from 453 CSA farms in Michigan, New York, Ohio, and Pennsylvania, CK estimated consumer valuations of CSA attributes, including product offerings, number of deliveries, number of pick up days per week, and production techniques such as organic certifications, integrated pest management and naturally grown certification. They found that consumers were willing to pay a $7 \%$ premium for certified organic produce. They also found consumers were willing to pay an $8 \%$ premium for CSA programs offering fresh-cut flowers in addition to fresh vegetables. However, premiums for CSA programs also offering fruits or animal products (dairy products, meat or eggs) in addition to vegetables were not statistically significant.

A key difference between CK and this paper is that CK do not control for potential price effects of contract type in their model; while they do control for "you pick," they do not control for the presence of weight shares. Perhaps this is because the variation in contract types found in our New England data set was not present in their sample. If varying contract types were present, then omitting contract type as a covariate may have biased their results. Except for addressing 
contract types, the analyses presented here are similar, as CK also use a hedonic pricing model to decompose farm-level prices into willingness to pay for attributes of the CSA contracts.

The remainder of the paper is organized as follows. The next section presents the pricing model for CSA contracts providing a basket of goods. The third section describes our data set and the fourth section presents the econometric model. The fifth and sixth sections present the econometric results and robustness checks, and the final section concludes.

\section{A Pricing Model for CSA Shares}

We present a simplified version of the SK model, using "risk-neutral" valuation from asset pricing theory, but not requiring the full general equilibrium framework of their paper. There are three basic CSA share types: yield shares, weight shares, and debit shares. Debit shares are purely a financing arrangement without risk management provisions for price and yield risks, so we focus here only on the price relationship between yield shares and weight shares. While SK present a more complex theory based on product-level expectations of prices and yields, we assume that shares cover a basket of different crops (e.g., a crop index), for simplicity. This is realistic because most CSA share agreements include an array of different products. All shares are purchased at time $t=0$ (planting time) with proceeds delivered at time $t=T$ (harvest time).

We model share pricing for a single farmer. Share prices across farms are expected to vary according to the number and type of products included, growing practices, and expectations about yield risk and product quality, among other factors. To clarify notation, we omit subscripts denoting the specific farmer whose shares are being referenced.

Yield shares are defined as providing single season ownership of some fraction of the farm, which produces yields as a random variable, $Y$, in units of the basket or index. The value of 
the yield share at harvest is therefore equal to the yield times the basket's spot price at harvest, $p_{T}$, or simply the realized revenue per share:

$$
R_{T}=Y \cdot p_{T}
$$

The yield share is assignable, so we assume it trades pre-season at spot price, $R_{0}$. Assuming complete markets and no-arbitrage, the spot price reflects the expectation under a unique, riskadjusted (aka risk-neutral) probability distribution, $\phi$ :

$$
R_{0}=E_{\phi}\left[R_{T}\right]
$$

Weight shares are defined as delivering a fixed quantity, $Y_{w}$, at a pre-arranged price, in the manner of a futures contract. The pre-arranged price is the futures price of the index, denoted $\hat{p}_{0}$, and it is also priced with respect to the risk-adjusted distribution $\left(\hat{p}_{0}=E_{\phi}\left[p_{T}\right]\right){ }^{1}$ The weight shares are thus priced according to:

$$
W_{0}=Y_{w} \cdot \hat{p}_{0}
$$

It is not guaranteed that the two contract types offer the same quantities in expectation, so it may be that $Y_{w} \neq E_{\phi}[Y]$. For example, Lapan and Moschini's (1994) model of farm production under risk implies optimal hedging in futures markets depending on the farmer's risk aversion, the yield-price covariance, and the basis risk. Even if farmers are identical except with respect to share type, the model is likely to imply different optimal hedges when futures markets (or weight shares) are used for hedging than when yield shares are used as a hedging instrument. To account for this, we let $\Delta Y=Y_{w}-E_{\phi}[Y]$ denote the difference between the weight share's fixed quantity, $Y_{w}$, and yield share's expected yield, $E_{\phi}[Y]$ 
In the case of weight shares, the seller is responsible to make up any quantity shortfalls on the open market, and therefore may bear more risk than under a yield share arrangement. While the forward/futures contract structure of the weight shares contract removes price risk, it also removes the natural hedge of prices against yields due to their negative correlation, which is induced by spatial weather correlations and supply-and-demand factors. Proposition 1 formalizes the price relationship between yield share and weight share contracts.

Proposition 1. Given complete markets with no arbitrage, the price relationship between weight shares and yield shares is given by:

$$
W_{0}-R_{0}=\Delta Y \cdot \hat{p}_{0}-\operatorname{Cov}_{\phi}\left[Y, p_{T}\right] .
$$

Proof of Proposition 1. The proposition follows from adding and subtracting identical terms, and then simplifying by (i) factoring out the yield-price covariance and (ii) substituting the futures price of the index for its risk-adjusted expectation.

$$
\begin{aligned}
W_{0}-R_{0} & =Y_{w} \cdot \hat{p}_{0}-E_{\phi}\left[Y \cdot p_{T}\right] \\
& =Y_{w} \cdot \hat{p}_{0}-E_{\phi}\left[Y \cdot p_{T}\right]+E_{\phi}[Y] E_{\phi}\left[p_{T}\right]-E_{\phi}[Y] E_{\phi}\left[p_{T}\right] \\
& =\Delta Y \cdot \hat{p}_{0}-\operatorname{Cov}_{\phi}\left[Y, p_{T}\right]
\end{aligned}
$$

Proposition 1 makes explicit the risk management differences of the two share types for farmers. Any price premium of weight shares has two components, a yield premium, $\Delta Y \cdot \hat{p}_{0}$, and a risk premium, $-\operatorname{Cov}_{\phi}\left[Y, p_{T}\right]$. The yield premium accounts for potential systematic differences in the expected yields between the two contract types, while the risk premium compensates the farm for the removal of price as a natural hedge on yield risk. Interestingly, the left hand side of Proposition 1 is a replicating portfolio for a cash transfer in the amount of 
$\Delta Y \cdot \hat{p}_{0}$ and a short covariance swap (e.g., as introduced in Carr and Madan, 1999) on yields and prices, in the hypothetical case where yields themselves are a tradable security. We find it a surprising result that our simple model yields the swap price, since execution of the covariance swap requires intermediate trading periods between $t=0$ and $t=T$, for hedging in the underlying securities.

Clearly, in cases where the (risk-adjusted) expected yield from the yield share is equal to the guaranteed quantity of the weight share contract $(\Delta Y=0)$, then the yield premium is zero and the price premium of weight shares (relative to yield shares) will be given by the covariance of yield and harvest price (exactly equal to the price of the covariance swap). That is, when both shares offer the same yield in expectation $\left(Y_{w}=E_{\phi}[Y]\right)$, then $W_{0}-R_{0}=-\operatorname{Cov}_{\phi}\left[Y, p_{T}\right]>0$. Put another way, if $\operatorname{Cov}_{\phi}\left[Y, p_{T}\right]<0$ (post-harvest spot prices are negatively correlated with yields), then weight shares will be more expensive unless they are expected to deliver a substantially smaller quantity than yield shares.

Econometric identification of the components of the price premium for weight shares requires knowing two of: (i) the price difference, (ii) the yield difference, and (iii) the price-yield covariance. In our data set, we observe only share prices: yield differences and price-yield covariance are not observable. However, the anecdotal evidence suggests that the weight shares are intended to give yields comparable to those of the expected, or typical, yields under the yield shares. Many of the CSA farms offering yield shares advertise when yields or revenues have been high. For example, Big Train Farm of Cranston, RI announces on their information page at farmfreshri.org, "2013 full-share members received nearly $\$ 80$ worth of produce over their initial 
investment!" None of the CSA farms offering weight shares in our sample give any advertisement that their quantities differ from what might be expected from a typical yield share.

Further, it can be shown that weight share prices will be comparable across farmers, subject to inclusion of the same products in the basket. Since weight shares are a zero-risk instrument for consumers, no arbitrage implies that (i) weight shares will be priced according to the sum of the expected prices of their components, and (ii) component prices will be equal across farmers, so long as committed yields, $Y_{w}$, and quality are held constant. Yield shares will not be identically priced across farmers, both because farmers will have different risk profiles for the same crop, and because farmers will have different "basket risk" profiles, arising from within-farm covariance of yields across crops.

\section{Data}

Farm Fresh Rhode Island is a non-profit organization that maintains an extensive online database of both CSA farms and non-CSA farms in New England. Farm-level data were collected directly from Farm Fresh Rhode Island's website (www.farmfreshri.org) and from individual farm website. In rare cases in which all of the pertinent information was not available on either Farm Fresh Rhode Island's website or the farm's website, information was obtained by calling the farm. Complete information was obtained for 226 CSA farms within a 150-mile radius of Providence, RI. We focus on New England for the analysis because the first U.S. CSA programs started in this area and hence CSA program have a long established history here.

CSA details including price, number of deliveries, and share type were determined by reading the farm's CSA share agreement. Many farms offer both "full" shares, designed to provide enough product for 4-5 people, and "half" shares, which provide enough product for 2-3 people. As shown in table 1 , on average, a full share costs $\$ 575.82$, while a half share costs 
\$356.77. The terms of the CSA share agreement and the length of the season tend to vary substantially from contract to contract. On average, the length of a season is approximately 20 weeks. In order to be able to compare share prices across CSA with different season lengths, we constructed the price per delivery by dividing the share price by the number of deliveries. The average price-per-delivery of a full share is $\$ 30.34$, while the average price-per-delivery of a half share is $\$ 18.89$. Because only about half of the farms in our sample offer both full and half shares (and none offer only half shares), we use only the full share price per delivery in the regression analysis.

As shown in table 2 , the majority of farms in our sample, approximately $80 \%$, offered yield shares. Only $5.75 \%$ of the farms offered debit shares and another $5.75 \%$ offered you-pick shares. Given the similarities of these two types of contracts, we combine debit shares and youpick shares into one group for the remainder of the analysis. The remaining $9.29 \%$ of farms offered weight shares. As shown in table 1, on average, the price per delivery of weight shares is higher than the price per delivery for the other two contract types. This is consistent with our theoretical model.

Almost half of the farms in the sample use chemical-free farming practices, as shown in table 2. An additional $21.24 \%$ use organic practices and $13.72 \%$ use integrated pest management techniques. The remaining $16.81 \%$ employ traditional farming practices. The majority of farms in the sample are located in Massachusetts, just over 10\% are located in Rhode Island and the rest are located in Connecticut.

Approximately $80 \%$ of CSA share agreements in our sample require members to pick up their shares at the farm. The pickup location for $7 \%$ of the CSA farms is a farmers market and approximately $13 \%$ of CSA programs require pickup at a location other than the farm or a 
farmers' market, such as a church or place of business. It should be noted that two CSA farms delivered products directly to their members. We included these two farms in the "other" category. Farms offering CSA programs typically also sell their products through other channels. Approximately half of the sample sells their products at a farm stand, over $60 \%$ sell their products at farmers' markets and approximately $50 \%$ sell their products to commercial vendors including wholesalers and retail outlets.

CSA farms offer a wide variety of products. Most CSA farms in the sample offer more than one product category to their members, making it is difficult to categorize a particular CSA program as a "vegetable" or "fruit" CSA program. Therefore, we constructed indicator variables to represent the CSA program's product offerings. As shown in table 2, over 93\% of CSA farms in our sample provide vegetables to their members, almost $70 \%$ provide fruits, approximately $75 \%$ provide herbs and nearly $60 \%$ provide flowers. Dry goods, dairy and/or meat products and eggs are offered less frequently; these percentages are similar to those found in Tegtmeier and Duffy's (2005) study of Iowa farms. The correlations between product offerings are summarized in table 3. Fruit and vegetable offerings are positively correlated. Almost all CSA programs that offer fruits also offer vegetables (98.8\%). However, only $73.2 \%$ of CSA programs offering vegetables also offer fruits. There is also a positive correlation between vegetables and herbs. In fact, herbs are only offered by CSA farms that also provide vegetables and $80 \%$ of CSA farms that offer vegetables also offer herbs. The provision of dairy and/or meat products is negatively correlated with fruits, vegetables, herbs and flowers. Only roughly 19\% of CSA that provide dairy and/or meat products also provide vegetables. This result is not surprising since the production of dairy or meat products is fundamentally different than the production of 
vegetables; these two tasks require different types of capital, production inputs, and labor skills, which inhibit the farms' ability to diversify across these product categories.

Only $6.64 \%$ of the farms in the sample were located in an urban area. The concept of a CSA program is grounded in linking consumers to their food source and farmers. As a result, CSA programs sometimes require members to "volunteer" on the farm. Some volunteers might help with the planting, others with weeding during the growing season and others with the harvest. Approximately $15 \%$ of the CSA farms in our sample required members to work on the farm a mandatory number of hours.

\section{Econometric Model}

Proposition 1 predicts that the price difference between yield shares and weight shares will be determined by two potentially competing factors, the yield premium and the risk premium. Given the anecdotal evidence discussed above, we expect that the yield premium will be near zero (though this is not testable directly in our data set) and that the risk premium will be positive (weight shares cost more) due to negative covariance of prices and yields. We conduct a regression analysis to test the resulting prediction that weight shares will be more costly, on average, and to estimate the extra cost under the assumption that the yield premium is zero.

Specifically, we model the price of a share as a function of the share type while controlling for other factors that affect share price, including the products produced by the farm and offered through the CSA program, the farming practices, the pick-up location, the state where the CSA farm is located, and other outlets through which the farm sells its products. We estimate the following equation using ordinary least squares (OLS).

$$
P_{i}=\beta_{0}+X_{i}^{\prime} \beta_{n}+\varepsilon_{i}
$$


where $P_{i}$ is the per delivery share price of a full share offered by farm $i . P_{i}$ is constructed by dividing the price of a full share by the number of deliveries (or pickups) per season. In cases where farms offered a sliding scale, we chose the median value. $\beta_{0}$ is a constant to be estimated. $X_{i}^{\prime}$ is a vector of variables describing the characteristics of the $i^{\text {th }}$ farm and $i^{\text {th }}$ farm's CSA contract, including share type, growing practices, products offered, and state where the farm is located. $\beta_{n}$ is a vector of coefficients on the farm characteristics to be estimated, and $\varepsilon_{i}$ is a normally distributed error term with mean 0 .

$X_{i}^{\prime}$ captures several important characteristics of the $i^{\text {th }}$ farm and the farm's CSA contract. All indicator variables take the value of 1 when true and 0 otherwise. Share type is represented by two indicator variables: Weight Share and Debit Share. Given the similarities in the contract structures between "you-pick" and debit shares, we categorize "you-pick" contracts as Debit Shares. Yield share is the excluded category in the estimation. Growing practices are represented by three indicator variables: Chemical-free, IPM (integrated pest management) and Organic (some or all products are certified organic). The excluded category is traditional production practices. Pick location is represented by three indicator variables: Farmers Market, Other Pickup, and Delivery. The excluded category is pickup located at the farm. We include several indicator variables representing the products offered through the CSA: Fruits, Vegetables, Herbs, Flowers, Dry Goods, and Dairy/Meat (dairy and/or meat) and Eggs.

We also included an indicator variable for Urban Farm which takes the value of 1 if the farm is located in an urban area and 0 otherwise. Work-trade indicates if members are required to work mandatory hours on the farm as part of their CSA membership. CSA Length captures the number of deliveries/pickups per season. Three indicator variables capture the other outlets through with the farm distributes its products: Sell Farm Stand, Sell Farmers Market and Sell 
Commercial. Sell Commercial captures sales to retail and/or wholesale outlets. We estimate the model both with and without state-level fixed effects for Massachusetts (MA) and Rhode Island $(R I)$; Connecticut $(C T)$ is the excluded state dummy.

Our econometric model is a basic hedonic pricing approach. Firm-level data, in this case the prices charged by the CSA farms, can only be used to estimate hedonic models if price-cost markups are first eliminated and the competitiveness of the market is established (Feenstra 1995). CK follow Breshnahan and Reiss (1991) to determine that individual farms within their data set lack market power and hence act as price-takers. Their findings provide support for an earlier study in a working paper by Lass, Lavoie, and Fetter (2005) who found that CSA farms exert only $2 \%$ of their potential market power. Unlike CK, we do not have data to explicitly test the competitiveness of the market, so we appeal to their findings in what follows. A comparison of our summary statistics to those presented in CK suggests that the CSA shares in both samples have generally similar characteristics, except with respect to the absence of information about weight shares.

\section{Econometric Results}

The results of the regression analysis are presented in table 4 . Nearly identical results are obtained for the two models (with and without state-level fixed effects), but we discuss only the coefficients from the fixed effects model in the discussion that follows.

We find share prices for weight shares are, on average, $\$ 11.93$ (38\%) higher per delivery than the price per delivery for a yield share. The coefficient is significant at the $95 \%$ level. According to Proposition 1, our regression coefficient estimates the net effect of the covariance between prices and yields (the risk premium) plus any systematic difference in expected yields (the yield premium). The result is consistent with the theory; the degree of risk transfer from 
farmers to consumers has a significant effect on the contract price. Consumers that share in more of the farm's risks pay less than consumers who only bear only the price risk. As we discussed above, the data do not permit separate identification of the yield premium and risk premium for weight shares, but we anticipate that the yield premium is small and may be zero, on average.

A number of the significant regression coefficients are consistent with classical economic theory regarding opportunity costs. For example, we find that farms using organic production practices charge significantly more per delivery $(\$ 3.74$, or $12 \%$, on average) than farms using standard production practices, consistent with the higher costs of production and certification, and with higher consumer willingness-to-pay for organic products. This result is similar to the estimated 7\% premium for organic CSA products found by CK. Beyond organics, CSA farms that sell their products at a farmers market charge, on average, $\$ 2.05$ more per delivery than farms that do not, presumably because their products command a price premium outside the CSA program. Urban farms do not charge a significant price premium, perhaps because additional land and labor costs from urban settings are offset by lower transportation costs and increased market access.

We find that price per delivery is negatively related to CSA Length; the longer the CSA length the lower the price per delivery. On average, every additional delivery lowered the perdelivery price by $\$ 0.58$, which was significant at the $99 \%$ level. This suggests there may be economies of scale, or at least, an element of fixed costs with declining average cost in the contract length. However, we do not find any statistically significant discount from required work on the farm (Work-trade). This is consistent with the findings of CK for CSA farms in Michigan, Ohio, Pennsylvania and New York, but contradicts the findings of Conner (2003) for farms in Ithaca, NY. Future research is needed to determine whether customers of work-trade 
CSA farms derive non-food benefits from working on the farm, or if other causes explain the lack of effect on share price.

We find that CSA contract prices were roughly constant across product offerings, in the sense that none of the product dummies were significantly different from zero, except for CSA farms offering dairy or meat products, who charge on average, $\$ 2.31$ more per delivery than farms not offering these products. This indicates that, on average, inclusion or exclusion of fruits, vegetables, herbs, cut flowers, dry goods, or eggs does not materially affect the per delivery price of a CSA contract in our sample. It is unlikely that the observed lack of statistical significance is due to a lack of statistical power, because of the relatively large sample size $(\mathrm{N}=226)$. Further, since both consumer tastes for these goods and the market prices of the goods span a wide range, the results suggest that CSA contracts may be targeting a specific value of deliverable product. Such a finding would be consistent with consumers having a fixed and separate budget for this type of spending, rather than incorporating CSA spending into a global optimization of consumption, as in the context of mental accounting (e.g., as in Thaler, 1985).

\section{Robustness of Results}

While the theoretical model speaks to no-arbitrage prices of the different share types, it does not speak to farmer behavior in terms of which type(s) of shares to offer. A farmer's decision about whether to offer each of the various share types will depend on personal risk preferences and on perceptions of price, yield and revenue risk relative to the market prices of the various shares. It may be the case that farmers of certain crop types are more likely to offer particular share types, given the risks faced, access to farm safety net programs, and consumer tastes.

To control for this selection problem, we estimate a logit model to predict the probability of offering each contract type as a function of farm characteristics and products offered. We use 
a standard, binomial logit and focus only on the yield share versus weight share choice. More specifically, the dependent variable in the logit regression takes the value of 1 if the contract is a yield share and 0 if the contract is a weight share. We find that farms offering dairy or meat products in their CSA implies a large decrease in the probability of offering yield shares. The opposite is true for vegetables. This is intuitive because a random mix of vegetables in their veggie box may be more appealing to consumers than a random amount of pork shoulder or lamb chops to be delivered. The results of the logit model estimation are presented in the first column of table 5 .

We then use the logit model predictions as a first-stage regression to control for selection into share type by product attributes and repeat the analysis presented in table 4 . The logit prediction is included as a right hand side variable, $\widehat{\operatorname{Pr}(Y)}$, representing the estimated probability of selecting into a yield share using all other farm and contract attributes. Table 5 also shows the results of our regression from table 4, but with "yield-share-probability-hat" added as an additional control. Use of the logit model for prediction and focusing only on yield shares versus weight shares reduces the number of observations to 123 . As a result, there is no longer enough variation in the data to include all of the farm and contract attributes and hence some of the covariates are dropped from the model; specifically, Organic, Urban Farm, Work-trade, and $R I$ are not included in this analysis. Table 5 shows that the selection effect (predicted yield share probability) is not a statistically significant predictor of contract price. However, after controlling for selection into contract type, there is no longer a statistically significant price effect of dairy/meat offerings. Nonetheless, after controlling for selection into contract type, the estimated price premium on weight contracts is $\$ 9.61$, which is within one standard error of our 
estimate of $\$ 11.93$ above. The returns-to-scale estimate of a $\$ 0.58$ discount per additional delivery is significant and unchanged after controlling for contract selection.

\section{Conclusion}

Since their introduction in New England area in the 1980s, community supported agriculture programs have become increasingly popular throughout the United States. These programs enable consumers to buy shares of a farm's production, and hence are an important part of local food systems and farm-to-table movements. However, they are also important risk management tools for farmers. In New England, a variety of share types have arisen with the share types differing in the degree to which risk is transferred from the producer to the consumer. Following SK, we evaluate the risk management features of these contractual arrangements in the context of asset pricing theory for CSA contracts that deliver a basket of goods. The theory predicts that the price difference between yield shares and weight shares will be determined by two potentially competing factors: (i) the yield premium, due to share types delivering different expected quantities, and (ii) the risk premium, due to farmers giving up price as a natural hedge against yield risk. We test the theory using a unique, cross-sectional dataset. We find that, as predicted by the model, risk transfer has a significant effect on the contract price: share prices for pre-specified weights are more expensive than shares that deliver a proportion of the farm's production because the consumer does not bear any of the farmer's yield risk.

Our findings have some limitations because we cannot control for the yield premium with the present data; however, anecdotal evidence suggests the yield premium is small or nonexistent. This, in turn, suggests the observed price differential is due to the risk premium, though further research and substantially more data are necessary to individually identify these factors. 
We also find significant evidence of discounting for longer seasons, and price premiums for organics and for CSA shares including dairy or meat products. Despite tremendous variety in product offerings, from fruits and vegetables to herbs, cut flowers, dry goods and eggs, we find that prices per delivery are relatively constant across shares. These findings are consistent with CK. Shares requiring members to work on the farm ("work trade") gave no significant discount, consistent with some but not all of their findings.

In addition, we find that CSA share prices are, with the exception of dairy and meat, not statistically related to CSA product offerings. Even dairy and meat do not affect share prices once factors influencing selection into contract types are properly controlled. This may suggest that consumers have some willingness to pay to support local agriculture, which then determines the amount they allocate to CSA contracts regardless of the products offered. In other words, the consumers' preferences are for local agriculture and not specific products. This is consistent with the finding of Farnsworth et al. (1996) who concluded that social or "club" benefits drive the decisions of members to join CSA. Our data set included limited information about social aspects of each CSA and hence further research is necessary to determine whether it is these "club" benefits or the multiplicity of product offerings that leads to the lack of statistical significant price effects for individual products in the regression analysis.

\section{References}

Bresnahan, T., and P.C. Reiss. 1991. "Entry and Competition in Concentrated Markets.” Journal of Political Economy 99: 977-1009.

Brown, A. 2002. "Farmers' Market Research 1940-2000: An Inventory and Review." American Journal of Alternative Agriculture 17(4):167-76. 
Brown, C. and S. Miller. 2008. "The Impacts of Local Markets: A Review of Research on Farmers Markets and Community Supported Agriculture (CSA)." American Journal of Agricultural Economics 90(5):1298-1302.

Carr, P. and D. Madan, 1999. "Introducing the covariance swap.” Risk February 1999: pp. 47-51.

Conner, D. S. 2003. Community Supported Agriculture Pricing and Promotion Strategies:

Lessons from Two Ithaca, NY Area Farms. Cornell University Department of Applied Economics and Management, Extension Bulletin 2003-07.

Connolly, C. and H. A. Klaiber. 2014. "Does Organic Command a Premium When the Food is Already Local?" American Journal of Agricultural Economics 96 (4):1102-1116.

Farm Fresh Rhode Island. 2015. A Hub for Fresh, Healthy Food. Pawtucket, RI. http://www.farmfreshri.org/

Farnsworth, R. L., S. R. Thompson, K. A. Drury, and R. E. Warner. 1996. “Community Supported Agriculture: Filling a Niche Market." Journal of Food Distribution Research 27: 90-98.

Feenstra, R.C. 1995. "Exact Hedonic Price Indexes." The Review of Economics and Statistics 77(4):634-653.

Fieldhouse, P. 1996. "Community Shared Agriculture.” Agriculture and Human 3:43-47.

Hull, J. Options, futures and other derivatives. Pearson education, 2009.

Lapan, H. and G. Moschini. 1997. "Futures Hedging under Price, Basis, and Production Risk." American Journal of Agricultural Economics 76(3):465-477. 
Lass D., A. Brevis, G. W. Stevenson, J. Hendrickson, and K. Ruhf. 2003. "Community Supported Agriculture Entering the 21st Century: Results from the 2001 National Survey." Working paper, Department of Resource Economics, University of Massachusetts.

Lass, D., N. Lavoie, and R. Fetter. 2005. "Market Power in Direct Marketing of Fresh Produce: Community Supported Agriculture Farms.” Working Paper 2005-2, Department of Resource Economics, University of Massachusetts. http://econpapers.repec.org/paper/drewpaper/2005-2.htm.

Lizio W. and D. A. Lass. 2005. “CSA 2001: An Evolving Platform for Ecological and Economical Agricultural Marketing and Production.” Working paper, Department of Resource Economics, University of Massachusetts.

Tegtmeier, E. and M. Duffy. 2005. "Community Supported Agriculture (CSA) in the Midwest United States: A Regional Characterization.” Leopold Center for Sustainable Agriculture, Iowa State University.

Sproul, T. W. and J. D. Kropp. "A General Equilibrium Theory of Contracts in Community Supported Agriculture.” American Journal of Agricultural Economics, forthcoming.

Thaler, R. 2008. "Mental Accounting and Consumer Choice.” Marketing science 4(3):199-214.

U.S. Department of Agriculture. 2014a. "2012 Census of Agriculture - Summary and State Data.” Washington, DC: USDA National Agricultural Statistics Service 558. http://www.agcensus.usda.gov/Publications/2012/Full Report/Volume 1, Chapter 1 U U $\underline{\text { S/usv1.pdf }}$ 
U.S. Department of Agriculture. 2014b. Community Support Agriculture. Washington, DC. http://www.nal.usda.gov/afsic/pubs/csa/csa.shtml

Wilkinson, J. 2001. “Community Support Agriculture.” OCD Technotes. Washington, DC: U.S. Department of Agriculture. Rural Development. http://rurdev.sc.egov.usda.gov/SupportDocuments/tn20_CSA.pdf 


\section{Endnotes}

${ }^{1}$ Futures prices models also use an assumption of no arbitrage. Fresh produce markets are not, however, like grain markets, because there is no reasonable means to enforce no-arbitrage relationships by buying spot produce for future delivery. For example, one cannot buy spot fresh strawberries and deliver them on a futures contract written six months from now. To address this, we assume the existence of complete markets for frozen produce with both spot and futures available. The frozen market price, $\pi_{t}$, is tied by a constant factor to the fresh market price, $p_{t}$, at all times, $t$, by consumer preferences regarding the substitutability of frozen and fresh products: $\pi_{t}=\theta \cdot p_{t}$, with $\theta \in(0,1)$. At time 0 , the spot and futures prices of frozen and produce are related by $\hat{\pi}_{0}=\left(\pi_{0}+U-C\right) e^{r T}$, where $U$ is a fixed cost of carry (by weight) and $C$ is a convenience yield, representing the cash value of holding physical inventory in the event of a shortage (c.f., Hull[2009], pp.115-120). The spot frozen price is the price of a traded asset, so it is equal to its discounted, expected value under the risk-adjusted distribution, with adjustments for carry cost and convenience yield: $\pi_{0}=E_{\phi}\left[\pi_{T}\right] e^{-r T}-U+C$. Thus, $\hat{\pi}_{0}=E_{\phi}\left[\pi_{T}\right]$, and the price relationship between fresh and frozen markets yields the implied futures price in the fresh market: $\hat{p}_{0}=\theta^{-1} \hat{\pi}_{0}=E_{\phi}\left[p_{T}\right]$. 
Table 1. CSA Contract Share Prices and CSA Length

\begin{tabular}{lrrrrr}
\hline Variable & Obs. & Mean & SD & Min & Max \\
\hline Full Share Price (\$) & 226 & 575.82 & 184.55 & 85 & 1820 \\
Full Share Price/Delivery (\$) & 226 & 30.34 & 8.85 & 4.62 & 65 \\
Half Share Price (\$) & 133 & 356.77 & 102.83 & 65 & 700 \\
Half Share Price/Delivery (\$) & 133 & 18.89 & 5.56 & 8.93 & 41.67 \\
Full Share Price/Delivery: Yield Shares (\$) & 184 & 29.59 & 7.67 & 4.62 & 62.50 \\
Full Share Price/Delivery: Weight Shares (\$) & 21 & 40.07 & 13.24 & 21.50 & 65.00 \\
Full Share Price/Delivery: Debit Shares (\$) & 26 & 26.66 & 6.90 & 11.76 & 36.92 \\
CSA Length (deliveries) & 226 & 19.68 & 6.23 & 4 & 52 \\
\hline
\end{tabular}

Note: Data were farm-level data for farms offering CSA located within a 150-mile radius of Providence, Rhode Island and listed on Farm Fresh Rhode Island's website (www.farmfreshri.org). 
Table 2. CSA Farm and Contract Characteristics

\begin{tabular}{|c|c|c|}
\hline Variable & Frequency & Percent \\
\hline \multicolumn{3}{|l|}{ Share Type } \\
\hline General Share & 179 & 79.2 \\
\hline Weight Share & 21 & 9.29 \\
\hline Debit Share & 13 & 5.75 \\
\hline You-Pick Share & 13 & 5.75 \\
\hline \multicolumn{3}{|l|}{ Farming Practices } \\
\hline Traditional & 38 & 16.81 \\
\hline Chemical Free & 109 & 48.23 \\
\hline Organic & 48 & 21.24 \\
\hline IPM & 31 & 13.72 \\
\hline \multicolumn{3}{|l|}{ State } \\
\hline $\mathrm{CT}$ & 59 & 26.11 \\
\hline MA & 143 & 63.27 \\
\hline RI & 24 & 10.62 \\
\hline \multicolumn{3}{|l|}{ Pick-up Location } \\
\hline Farm & 180 & 79.65 \\
\hline Farmers Market & 16 & 7.08 \\
\hline Other & 30 & 13.27 \\
\hline \multicolumn{3}{|l|}{ CSA Products } \\
\hline Fruits & 157 & 69.47 \\
\hline Vegetables & 211 & 93.36 \\
\hline Herbs & 170 & 75.22 \\
\hline Flowers & 132 & 58.41 \\
\hline Dry Goods & 88 & 38.94 \\
\hline Dairy/Meat & 69 & 30.53 \\
\hline Eggs & 85 & 37.61 \\
\hline \multicolumn{3}{|l|}{ Other Characteris tics } \\
\hline Urban Farm & 15 & 6.64 \\
\hline Work Trade Mandatory & 33 & 14.60 \\
\hline Sells Farm Stand & 110 & 48.67 \\
\hline Sells Farmers Market & 137 & 60.62 \\
\hline Sells Commercial & 112 & 49.56 \\
\hline Observations & & \\
\hline
\end{tabular}

Note: Data were farm-level data for farms offering CSA located within a 150-mile radius of Providence, Rhode Island and listed on www.farmfreshri.org. A condensed version of this table appears in Table 1 of Sproul and Kropp (2014). 
Table 3. Correlations between CSA Product Offerings

\begin{tabular}{|c|c|c|c|c|c|c|c|}
\hline & Fruits & Vegetables & Herbs & Flowers & Dry Goods & Dairy/Meat & Eggs \\
\hline Fruits & 1.0000 & & & & & & \\
\hline Vegetables & 0.3636 & 1.0000 & & & & & \\
\hline Herbs & 0.2871 & 0.4646 & 1.0000 & & & & \\
\hline Flowers & 0.2008 & 0.2438 & 0.2227 & 1.0000 & & & \\
\hline Dry Goods & 0.1747 & -0.0058 & 0.0379 & 0.1215 & 1.0000 & & \\
\hline Dairy/Meat & -0.0612 & -0.3250 & -0.2204 & -0.0838 & 0.1997 & 1.0000 & \\
\hline Eggs & 0.0982 & -0.1966 & -0.1256 & 0.0436 & 0.2230 & 0.4968 & 1.0000 \\
\hline
\end{tabular}

Note: Data were farm-level data for farms offering CSA located within a 150-mile radius of Providence, Rhode Island and listed on www.farmfreshri.org. This table is reproduced from Table 2 of Sproul and Kropp (2014). 
Table 4. Regression Results

\begin{tabular}{|c|c|c|}
\hline Weight Share & \begin{tabular}{c}
\multicolumn{1}{c}{$(1)$} \\
$11.9388^{* * *}$ \\
$(4.0590)$
\end{tabular} & $\begin{array}{c}c(2) \\
11.9244^{* * *} \\
(4.1567)\end{array}$ \\
\hline Debit Share & $\begin{array}{l}-2.3068 \\
(1.5462)\end{array}$ & $\begin{array}{l}-2.3629 \\
(1.5488)\end{array}$ \\
\hline Chemical-free & $\begin{array}{l}0.4440 \\
(1.6040)\end{array}$ & $\begin{array}{l}0.6388 \\
(1.6062)\end{array}$ \\
\hline Organic & $\begin{array}{l}3.4531 * * \\
(1.6719)\end{array}$ & $\begin{array}{l}3.7428 * * \\
(1.7203)\end{array}$ \\
\hline IPM & $\begin{array}{l}1.7242 \\
(1.8046)\end{array}$ & $\begin{array}{l}1.9884 \\
(1.8373)\end{array}$ \\
\hline Farmers Market & $\begin{array}{l}-1.9506 \\
(2.6747)\end{array}$ & $\begin{array}{l}-1.9424 \\
(2.6342)\end{array}$ \\
\hline Other Pickup & $\begin{array}{l}-1.3226 \\
(1.4192)\end{array}$ & $\begin{array}{l}-1.4559 \\
(1.4617)\end{array}$ \\
\hline Fruits & $\begin{array}{l}-0.7120 \\
(1.1277)\end{array}$ & $\begin{array}{l}-0.7177 \\
(1.1328)\end{array}$ \\
\hline Vegetables & $\begin{array}{l}4.9051 \\
(4.8444)\end{array}$ & $\begin{array}{l}5.0938 \\
(4.9477)\end{array}$ \\
\hline Herbs & $\begin{array}{l}1.9985 \\
(1.4335)\end{array}$ & $\begin{array}{l}1.8055 \\
(1.5098)\end{array}$ \\
\hline Flowers & $\begin{array}{l}0.5170 \\
(1.1073)\end{array}$ & $\begin{array}{l}0.4919 \\
(1.1183)\end{array}$ \\
\hline Dry Goods & $\begin{array}{l}0.6743 \\
(1.1968)\end{array}$ & $\begin{array}{l}0.6010 \\
(1.2018)\end{array}$ \\
\hline Dairy/Meat & $\begin{array}{l}2.3587^{*} \\
(1.3294)\end{array}$ & $\begin{array}{l}2.3069^{*} \\
(1.3575)\end{array}$ \\
\hline Eggs & $\begin{array}{l}0.1906 \\
(1.4449)\end{array}$ & $\begin{array}{l}0.1832 \\
(1.4841)\end{array}$ \\
\hline Urban Farm & $\begin{array}{l}-0.5562 \\
(2.1696)\end{array}$ & $\begin{array}{l}-0.2677 \\
(2.2441)\end{array}$ \\
\hline Work-trade & $\begin{array}{l}-0.7541 \\
(1.3458)\end{array}$ & $\begin{array}{l}-0.8459 \\
(1.3297)\end{array}$ \\
\hline
\end{tabular}


Table 4. Continued

\begin{tabular}{lll}
\hline & \multicolumn{1}{c}{$(1)$} & \multicolumn{1}{c}{$(2)$} \\
Sell Farm Stand & 0.6622 & 0.6163 \\
Sell Farmers Market & $(0.9778)$ & $(0.9902)$ \\
& $2.0473 * *$ & $2.0452^{*}$ \\
Sell Commercial & $(1.0354)$ & $(1.0534)$ \\
& -0.6459 & -0.6027 \\
CSA Length & $(1.1243)$ & $(1.1445)$ \\
& $-0.5725^{*} * *$ & $-0.5772 * * *$ \\
MA & $(0.1284)$ & $(0.1311)$ \\
& & 1.0324 \\
RI & & $(1.1370)$ \\
Intercept & & 0.2223 \\
& & $(2.6086)$ \\
Obs. & $31.8580^{* * *}$ & $31.1377 * * *$ \\
$\mathrm{R}^{2}$ & $(5.3027)$ & $(5.4226)$ \\
F & 226 & 226 \\
Log-likelihood & 0.3499 & 0.3524 \\
\hline
\end{tabular}

Note: Data were farm-level data for farms offering CSA located within a 150-mile radius of Providence, Rhode Island and listed on Farm Fresh Rhode Island's website (www.farmfreshri.org). Asterisk (*), double asterisk $(* *)$, and triple asterisk $(* * *)$ denote 10, 5 , and 1 percent significance levels, respectively. Standard errors are in ( ). 
Table 5. Controlling for Selection of Contract Offerings

\begin{tabular}{|c|c|c|}
\hline & $\begin{array}{c}\text { First-stage } \\
\text { Logit }\end{array}$ & $\begin{array}{c}\text { Second-stage } \\
\text { OLS }\end{array}$ \\
\hline$\widehat{\operatorname{Pr}(Y)}$ & & $\begin{array}{l}-12.7622 \\
(13.3430)\end{array}$ \\
\hline Weight Share & & $\begin{array}{l}9.6123 * * \\
(4.1024)\end{array}$ \\
\hline Chemical-free & $\begin{array}{l}0.4765 \\
(1.1880)\end{array}$ & $\begin{array}{l}1.1964 \\
(1.9131)\end{array}$ \\
\hline IPM & $\begin{array}{l}1.0179 \\
(1.4301)\end{array}$ & $\begin{array}{l}2.8484 \\
(2.4919)\end{array}$ \\
\hline Farmers Market & $\begin{array}{l}0.9227 \\
(4.6862)\end{array}$ & $\begin{array}{l}8.3533^{*} \\
(4.7115)\end{array}$ \\
\hline Other Pickup & $\begin{array}{l}0.4635 \\
(1.2967)\end{array}$ & $\begin{array}{l}-0.7211 \\
(1.9348)\end{array}$ \\
\hline Fruits & $\begin{array}{l}-0.5965 \\
(1.3243)\end{array}$ & $\begin{array}{l}0.0116 \\
(1.4555)\end{array}$ \\
\hline Vegetables & $\begin{array}{l}4.6514^{* *} \\
(1.8609)\end{array}$ & $\begin{array}{l}9.4427 \\
(8.4736)\end{array}$ \\
\hline Herbs & $\begin{array}{l}0.4826 \\
(1.1049)\end{array}$ & $\begin{array}{l}3.2412 \\
(2.0294)\end{array}$ \\
\hline Flowers & $\begin{array}{l}1.0275 \\
(0.8937)\end{array}$ & $\begin{array}{l}1.0712 \\
(1.9321)\end{array}$ \\
\hline Dry Goods & $\begin{array}{l}1.1170 \\
(0.9731)\end{array}$ & $\begin{array}{l}0.7458 \\
(1.6255)\end{array}$ \\
\hline Dairy/Meat & $\begin{array}{l}-2.6871 * * * \\
(1.0407)\end{array}$ & $\begin{array}{l}-1.0752 \\
(3.0714)\end{array}$ \\
\hline Eggs & $\begin{array}{l}-0.6560 \\
(0.9784)\end{array}$ & $\begin{array}{l}1.0373 \\
(2.0435)\end{array}$ \\
\hline Sell Farm Stand & $\begin{array}{l}-1.6450 \\
(1.2016)\end{array}$ & $\begin{array}{l}0.6046 \\
(1.7761)\end{array}$ \\
\hline Sell Farmers Market & $\begin{array}{l}-0.5461 \\
(1.1222)\end{array}$ & $\begin{array}{l}2.2276 \\
(1.4439)\end{array}$ \\
\hline Sell Commercial & $\begin{array}{l}0.2997 \\
(0.9389)\end{array}$ & $\begin{array}{l}-1.8206 \\
(1.5189)\end{array}$ \\
\hline
\end{tabular}


Table 5. Continued

\begin{tabular}{lll}
\hline & \multicolumn{1}{c}{$\begin{array}{c}\text { First-stage } \\
\text { Logit }\end{array}$} & \multicolumn{1}{c}{$\begin{array}{c}\text { Second-stage } \\
\text { OLS }\end{array}$} \\
\cline { 2 - 2 } CSA Length & $\begin{array}{l}\text { O.0008 } \\
(0.0836)\end{array}$ & $\begin{array}{l}-0.5805^{* * *} \\
(0.1610)\end{array}$ \\
MA & -0.2766 & 0.7317 \\
& $(0.9809)$ & $(1.6665)$ \\
Intercept & -0.4417 & $37.0218^{* * *}$ \\
Obs. & $(2.8094)$ & $(7.3751)$ \\
$\mathrm{R}^{2}$ & 123 & 123 \\
Log-likelihood & & 0.4422 \\
\hline
\end{tabular}

Note: Data were farm-level data for farms offering CSA located within a 150-mile radius of Providence, Rhode Island and listed on Farm Fresh Rhode Island's website (www.farmfreshri.org). Asterisk (*), double asterisk $(* *)$, and triple asterisk $(* * *)$ denote 10, 5, and 1 percent significance levels, respectively. Standard errors are in ( ). 